\title{
What Makes Environmental and Sustainability Education Transformative: A Re-Appraisal of the Conceptual Parameters
}

\author{
Niranjan Casinader
}

Citation: Casinader, N. What Makes Environmental and Sustainability

Education Transformative: A Re-Appraisal of the Conceptual Parameters. Sustainability 2021, 13, 5100. https://doi.org/10.3390/ su13095100

Academic Editors: Nicola Walshe and Louise Sund

Received: 7 April 2021

Accepted: 28 April 2021

Published: 1 May 2021

Publisher's Note: MDPI stays neutral with regard to jurisdictional claims in published maps and institutional affiliations.

\begin{abstract}
As with all educational policy and practice, Environmental and Sustainability Education, if it is to be effective and meaningful, has to be designed and implemented in ways that reflect twenty-first-century circumstances, which are characterized by a globalized society in which cultural diversities amongst individuals and populations have become increasingly more complex and prominent. Using a conceptual and philosophical analysis of the research and policy literature, this paper contends that current ESE tends to be trapped within a restrictive monocultural definition of sustainability that does not reflect the different cultural perspectives towards sustainability that exist across global populations as a whole. It further argues that if ESE is to become truly transformative for students, ESE teachers need to develop a transcultural capacity as part of their professional expertise, one that is more aligned with the reality of a more culturally diverse population and student body. Only then can transformative and effective ESE pedagogies be developed that relate more closely to the socio-political context in which students of today will live.
\end{abstract}

Keywords: sustainability; sustainable development; cultural diversity; teacher quality; transculturalism; educational transformation; Environmental and Sustainability Education

\section{Introduction}

As the twenty-first-century has progressed, one of the more dominant trends of school education has been a growing awareness that education in this era has an increasing obligation to prepare students for life in a world with two distinct characteristics: the dynamism and complexity of global societal change, and a new context in which the assumptions that had guided past decision-making are becoming increasingly questioned [1,2]. This is true for the teaching of Environmental and Sustainability Education (ESE) as much as any other area of learning and teaching.

The challenges of addressing such dramatic changes in societal processes through education are now often phrased in terms of the need for transformation. However, the exact nature of educational transformation, or the types of criteria that make an educational phenomenon transformative, are not universally agreed upon concepts, and its meaning is often highly debated [3] (p. 2). As an abstract concept, the idea of a transformation incorporates a complete change or shift from what has gone before, with the implication that the result has been an improvement on what has been in place previously. In the current period, writers have often summarised this paradigmatic shift as meaning that students now need to be taught twenty-first-century skills to enable them to meet the demands of this new twenty-first-century global society [4]. However, beyond this general implication, there are diverse opinions on what or who determines the nature or degree of that change.

In general education, it can be argued there have generally been two ways in which a transformative type of change has been perceived. Both trends focus on the common criterion that transformation involves a distinct break from existing patterns [5,6]. Within this general frame, the first interpretation has tended to focus predominantly on the processes of teaching, or pedagogy, whereas another centers more on the impact of these techniques and 
processes on changing student outcomes; however, they are measured. Thus, Lynch and Curtner-Smith posited that the goals of transformative pedagogy should be to "promote students' self-examination of their core values and beliefs and an understanding of those who have different core values and beliefs from their own" [7] (p. 360). Coutts extended this further by focusing on student engagement whilst also "acknowledging students' experiences and emotions while helping them to transform any problematic perspectives that might be inhibiting their learning" [8] (p. 496). In particular, the debate has reflected on whether the notion of transformation is defined by the effect of the pedagogy on student learning or in the nature of the pedagogical approach itself; for many, it is the former, or what has been changed or transformed within the individual student. For others, instead of the pedagogy being the catalyst of change, it is instead the educator as a person who may be transformative [7] (pp. 360-361).

In the specific educational field of ESE, notions of transformative pedagogy have tended to be more specific. Generally, ESE researchers have taken the line that the transformation that takes place as a result of the educational initiative has to be within the student, with particular emphasis on ESE being seen and used as a vehicle for developing student abilities in critical thinking about social justice and ethical considerations: "empower(ing) students to critically examine beliefs, values, and knowledge with the aim of developing new epistemologies, center multiple ways of knowing, and develop a sense of critical consciousness and agency" [9] (p. vii). Other ESE researchers, such as Hajer et al. argue that this is the only way in which the Sustainability Development Goals (SDG), developed through the auspices of the United Nations, can be addressed educationally, as it enables students to become more cognisant and aware of the importance of engaging all relevant stakeholders in matters of sustainability: "not only governments but other agents of change such as businesses, cities, citizens and civil society" [10] (p. 1653). It is in relation to such considerations that the potential for compatible links between ESE and global citizenship education has been noted [11,12].

It is problematic, however, that these educational interpretations of transformation, both general and ESE-related, tend to marginalize two key considerations. The first is that the educational focus on transformation has been predominantly on the pedagogical approach adopted by teachers and the impact of these on student outcomes, but not on the professional expertise of the teachers themselves to develop effective ESE, especially in relation to the contexts in which ESE education is taking place. As will be discussed in the next section, the issue of teacher quality has been one of the particular universal concerns over the last decade or more. If pedagogy is to be developed with transformation in mind, then policymakers need to ensure that teachers have the foundational skills and knowledge to do so in the present as well as in the medium- and long-term future. This applies to teachers of ESE as much as any other area of learning.

The second problem is that, regardless of whether ESE transformation is studentcentered or revolves around the actions of the teacher, as in the case of pedagogical change, the wider discussion does not take into account the notion of educational transformation is essentially a value-dependent construct; it is dependent upon the context in which the change has taken place. What appears to be a dramatic shift in one era may be seen as being no more than self-evident in another, and what appears to be transformative in one socio-economic context is not necessarily able to be classified as such in a different instance. The signifier, or signifiers, of what makes any particular pedagogical change transformative, therefore, depends very firmly on the conception of what is meant by 'transformation' in the context of the focus of the transformation. Since context can be both temporal and spatial, in that it incorporates perspectives that are both time and place-specific, the mark of educational transformation cannot be assumed to be constant from place to place. Included in that context is the demographic, cultural environment, and it is this particular aspect of educational transformation in the area of ESE that is of especial concern in the modern era.

Consequently, the theme of this paper, which takes the form of conceptual and theoretical analysis based on philosophical consideration of existing literature on ESE theory 
and practice, is the primary importance of placing a high priority of cultural context to the development of transformative ESE teaching and learning. Using the concepts of transculturalism and transcultural capacity as a background framework, this paper contends that effective ESE in the modern era will not be possible until it acknowledges the reality that contemporary notions of sustainability and ESE tend to omit consideration that cultural perspectives are contextual and vary from place to place; they are not universal. It must then also prioritize the teaching of ESE by teachers who have demonstrated transcultural capacity. It is this element of professional expertise that will enable the effective teaching of ESE in the different cultural contexts that characterize twenty-first-century global society and varying interpretations of ESE principles. What makes a pedagogy transformative, whether in ESE or in any other educational field, is the degree to which it reflects or instigates a new perspective on the world being studied. In the modern era, that new perspective is not just exemplified by notions of a global perspective, but also in the capacity of teachers to incorporate the implications of that global perspective into their broader educational attitudes and approach, which is a key aspect of personal and professional transcultural capacity.

\section{Sustainability, Cultural Context, and Transculturalism}

\subsection{Sustainability and Cultural Context}

It is now well accepted that one of the major impacts of modern globalization since the early 1990s has been the increasing cultural complexity and diversity of populations across the world. In the same vein, there has been an increasing, if slow-moving, movement towards the reality that these cultural intricacies demand a greater awareness and incorporation of respect for that cultural diversity in educational initiatives and implementation. Consequently, for ESE education to be truly transformative in the twenty-first century, it needs to incorporate a world perspective that not only acknowledges cultural diversity, but also implements and incorporates that perspective into the attitudes of the teachers who are implementing those pedagogies.

To date, however, it is arguable that conceptions of sustainability-and therefore ESE itself-have not fully acknowledged the reality of that global demographic complexity; they have attempted to be culturally neutral rather than culturally inclusive. In this context, inclusivity does not just mean that conceptions of sustainability used in education have to be diverse in their construction themselves; it also refers to the principle that sustainability needs to recognize and acknowledge the possibility and reality of culturally diverse interpretations of sustainability. The premise behind this argument, which, in essence, is that cultural context is an important consideration in societal issues, is not new in itself. For instance, standard transdisciplinary research (for example, see [6,13]) highlights the importance of taking into account 'the particularity of local culture' [14] (p. 104). Within Geography, others argue that the nature of geographical fieldwork both demands and facilitates the evaluation of cultural context, especially in ESE [15].

A major example of how the cultural context of sustainability has been minimized in current formulations of ESE is illustrated by what is arguably the most significant justification for ESE to be taught as a key component of school education: the United Nations Sustainability Development Goals (SDGs), which can be seen to both be a consequence or reflection of a dominant global opinion about how future interactions between people and the planet on which they live need to take place [16]. The SDGs tend to encompass two general elements in their construction of sustainability. First, there is the notion of sustainability as reflecting a responsibility towards future generations, in which sustainable development is defined as "development that meets the needs of the present without compromising the ability of future generations to meet their own needs" [17].

Secondly, the SDGs make a clear statement that sustainability is not just a consideration of the natural environment, but also how that environment is used in the goal of improving life existence across facets of human life and society, with a specific emphasis on equality, equity, and social justice: "Sustainable development calls for concerted efforts towards 
building an inclusive, sustainable and resilient future for people and planet" [9]. In short, it is a classic reflection of democratic iterations of educational philosophy that date back to the work of John Dewey [18].

Educationally, the values inherent in such a notion of sustainability have an underlying holistic theme; there is an emphasis on global unity and/or interdependence of global society, with the natural environment offering a base point that educators might use as a foundation for ESE: "sustainable development is a process of economic and social change designed to produce an environmentally sustainable economy and a just society" [17]. However, expressions such as Maude's "a just society" [19] (p. 19) are problematic in themselves, as they imply that there is one particular form of societal justice that is a self-evident goal for all. This lack of nuance minimizes, and even ignores, the reality that notions about the nature of a just society are not universal; indeed, opinions about the nature of 'justice' and its implications for human community and society are as diverse as the variety of expressed perspectives about culture and cultural heritage. Within whose value framework, then, are judgments about a just, sustainable society being made? When does it become valid, if ever, for one particular cultural perspective to hold sway in a global socio-political environment that champions the rights of separate and group cultural identities for self-determination and self-expression?

Similar false visions as to the uniformity and independence of cultural ways of thinking are reflected in other educational spheres. One of the most prominent of these are the Programme for International Student Assessment (PISA) programs conducted through the OECD [20], the bona fides and accuracy of which are promoted as aiming for as much cultural neutrality as possible [21,22]. However, as has been argued elsewhere [23-25], such assumptions are essentially illusionary; all cultures have values and priorities built into them that determine an individual's perspective on the world around them, and any attempt to devise an even partially culturally neutral entity, as opposed to openly and fully acknowledging and allowing for differences in cultural outlook, is relying misleadingly on either a belief that all cultures have the same value base or an assumption that there is a natural uniformity across cultures in people's attitudes that is self-evident. In the case of sustainability and ESE, there appears to be a rejection, or, at best, an unawareness, that there is a certain degree of cultural variation about the conceptions and implementation of sustainability concepts, where attitudes and thoughts about sustainability can even vary within the one cultural group. How these variations are reflected in reality will be considered more deeply as part of the discussion in the next section.

\subsection{Transculturalism and Cultural Context}

In recent years, teacher quality has become one of the central features of school education research and governance. Amongst modernized economies ranging from Australia, New Zealand, the United Kingdom, the European States, Singapore, and India, this has been translated into governments putting in place widely implemented regulatory measures designed to monitor and improve the work of teachers. Invariably, such measures have included sets of professional standards for teachers that guide both teacher education and teacher accreditation, such as the Australian Professional Standards for Teachers [26], as well as the provision of considerable funding for ongoing professional learning, often through statutory authorities, of which the Australian Institute for School Teaching and Leadership [27] and the National Institute of Education in Singapore [28] are prime examples.

However, within these myriad sets of professional checks, relatively little space has been allocated to addressing whether teachers have the specific personal and professional expertise in teaching cultural understanding in a manner that reflects the demographic, cultural complexities of the modern era. Too often, such expertise is assumed to be incorporated into standards about teachers having a professional duty to be aware of the various factors that may influence student experiences and outcomes in education, including gender, ethnic background, socio-economic status. In Australia's case, teacher 
accreditation in cultural understanding is restricted to one of eight Professional Standards that is centered along teachers knowing their students, plus two specific descriptors across all the Standards that refer to specifically about understanding the teaching of Aboriginal and Torres Strait Islanders [26]. It is assumed that such prescribed educational elements will be sufficient in a world where demographics, cultural diversity, and heritages are becoming ever more complex.

The argument that approaches to teacher education and ongoing professional development need to be reconfigured in order to meet the necessity of transforming school education, ESE included, has been a feature of the relevant discourse for some years (for example, $[4,29,30])$. Within this broad area, the specific case that the education and training of teachers in cultural understanding are far from adequate in the modern context is a theme that has formed a key plank in my published research over the last decade or more (for example, $[23,31-33]$ ). Space does not permit a full explication of the argument within this paper, but the key features of the contention are as follows. Its relationship to the teaching of ESE, and the cultural tunnel within which current ESE tends to be framed, will be addressed in the next section.

The complex nature of cultural diversity in populations in most countries of the world in the present age demands a cultural capacity within teachers that goes beyond the past and existing paradigms of multi- and interculturalism, regardless of what subjects they may be teaching, including ESE. Both these existing frames of cultural understanding and education are conceptually wanting in the current age because they are both premised on the belief that cultural differences are problems that need to be surmounted; they are difficulties founded on divisions between cultures. Such premises are not unexpected as they both reflect the times of their origins, which predate the era of contemporary globalization that began in the early 1990s, multiculturalism in the 1960s, and interculturalism in the 1970s. It was not until the 1990s that the past spatial separations of human cultures and heritages began to become less distinct and fluid as migration and work patterns changed in response to the growing incorporation of national economies and societies into a more interdependent and integrated whole. Despite such disparities, both multiand interculturalism still underpin current programs in student cultural education and teacher education. These can be seen in the phrasing and emphases of national curriculum statements in countries such as Australia [34], New Zealand [35], and Singapore [36], as well as European initiatives, to develop teacher expertise in cultural education [37].

The essence of a transculturalist approach to teaching, as well as the personal and professional capacities of teachers to implement such an approach, is that it entails a shift in attitude on the part of the teacher; it is not just the acquiring of competency through a certification or professional learning process; cultural differences within a population (or school class) are not just barriers to be overcome. Instead, cultural difference in society is perceived and treated as the natural state of that society; difference is expected, absorbed, and managed with a positive frame of mind. The transcultural focus on a shift in attitudes within the individual is a key separator from multi- and interculturalism, with those two approaches tending to stress knowledge and awareness about cultural 'Others' as points of achievement. However, knowing about the nature of cultures and communication between them is but a job half completed; transculturalism builds on those prior stages to develop a more conscious awareness of cultural nuance as a point of opportunity, not a dilemma, to acquire an attitudinal capacity towards teaching and learning that looks beyond the common 'place culture' mindset. In that sense, the development of transcultural capacity in teachers and its ongoing maturation through experience and professional learning provide a truly transformative foundation for any educational program, including those in ESE. They learn to "think differently about difference" [38] (p. 1), enabling themselves to "foster (their) own self-awareness and open-mindedness about difference before working with students to foster theirs" [38] (p. 2).

To that end, the specific contention of this paper is that ESE education and ESE teachers need to become far more transcultural in their educational perspective, rather than to make, 
perhaps unconsciously, prior assumptions about the nature of sustainability in relation to the cultural context, in which sustainability is seen to be a culturally neutral concept that does not warrant specific attention to the validity of differences in ESE conceptions and implementation. In short, ESE teachers need to be far more culturally contextual to the needs of students in their learning area, the global nature of education in general, as well as the specific community context of the school in which they are working.

\section{Discussion}

In arguing for a remodeled approach to ESE that is founded on transculturalism, the overriding factor is one of societal relevance. The teaching of ESE cannot be divorced from the wider context of what education in the twenty-first-century century needs to acknowledge: the reality of increasing complexity of cultural heritages, both of individuals and society, a characteristic that is very much part of an interdependent global society. The author acknowledges here that recent years have highlighted the flaws of contemporary globalization through such phenomena as the emergence of strong populist and nationalistic political leaders, but that is a debate for a different forum.

In broad terms and as expressed by the United Nations, through the SDGs, which can be seen to be the foundation of modern ESE, the idea of sustainability has three main aspects: "economic growth, social inclusion and environmental protection. These elements are interconnected, and all are crucial for the well-being of individuals and societies." [16]. The difficulty here is that, whilst it acknowledges that all cultures "and civilizations can contribute to, and are crucial enablers of, sustainable development" [39], such terminology avoids addressing the inevitability of what to do if cultural priorities clash, even though the underlying implication of the phrase of social inclusion is that there are multiple views that need to be acknowledged and incorporated. Instead, the language defaults to a reiteration of the broad goals of a sustainable society expressed in a democratic conception of sustainability that is based on 'Western' values:

"By 2030, ensure that all learners acquire the knowledge and skills needed to promote sustainable development, including, among others, through education for sustainable development and sustainable lifestyles, human rights, gender equality, promotion of a culture of peace and non-violence, global citizenship and appreciation of cultural diversity and of culture's contribution to sustainable development." [39]

In doing so, the assumption is made that there is an ultimate universality in the nature and processes of sustainable development and that the same exists for ESE. That universal perception is guided by the values of a socio-economic model that dominates current global thinking and action; a global economy based on an integrated trade system that promotes industrialized economic growth and therefore sees sustainability in that context.

Consequently, I contend that the major conundrum that ESE is facing, and the major barrier to genuinely transformative ESE, is one of global relevance; that is, the broad framework of ESE tends to avoid the inevitability that it is, like all educational policy, fundamentally a cultural construct. As a result, ESE tends to default into an overly simplified, environmentally framed Euro-American or 'Western' notion of sustainability that emphasizes conservation of the natural environment as the prime guiding factor in future human social and economic development, without ever really addressing the underlying dilemma of how to achieve improved living standards for all in a global context of diverse cultural perspectives.

The nature of this limited cultural perspective can be clearly seen in sustainability case studies around indigenous cultures. One example can be seen in a 2020 major review of Australia's Environment Protection and Biodiversity Act, which is an illustration of the type of government policy that is generally accepted as being central to the principle of sustainability in Euro-American cultural perspectives. One of the review's major conclusions and criticisms was that the legislation prioritized only one cultural perspective:

"Western science is heavily prioritised in the way the EPBC Act operates. Indigenous knowledge and views are diluted in the formal provision of advice to decision-makers. 
This reflects an overall culture of tokenism and symbolism, rather than one of genuine inclusion of Indigenous Australians." [40] (p. 6)

An assumption of cultural priority is particularly noticeable in situations where different indigenous perspectives are in play, a theme that ESE in Euro-American constructs tends to minimize, despite the importance that it also places, somewhat paradoxically, on indigenous inclusivity in socio-political policy. One more recent example illustrates how sustainability can be interpreted so very differently within one cultural context, let alone between multiple contexts. Within the Macuxi tribe in the Amazonian state of Roraima, Brazil, the people are split into groups that have very different ideas on how to enact their rights of self-determination in building a sustainable future for themselves and the place of mining tribal lands in achieving that goal. Whereas one group favors its authorization in order to provide the financial base for modernization of tribal life, another is far more resistant to the approach, being concerned about the environmental impacts of such a strategy on the sanctity of tribal homelands and the Amazonian rainforest [41].

In another example that highlights the differences between indigenous outlooks on sustainability and more Euro-American perspectives, a recent Australian report [42] highlighted that sustainability, in terms of Australian and Torres Strait Islander perspectives, contains a specific rejection of Euro-American modern capitalism in its imperative that it is essential that people's spiritual links to Country are maintained:

"Our practices and tools bring people together to value the ancient and continuing knowledge and wisdom of First Nations/Indigenous Peoples in the ecologically sustainable development and management of land, sea, skies and waterways in Australia and across the world...

The sustainability of our lives on Country is dependent upon our knowledge systems ... Indigenous Peoples and partners in other countries who also seek ways to keep culture and connections with Country alive, overcoming the challenges posed by colonisation, industrialisation and capitalism." [43] (4)

The use of Indigenous knowledge in the process is also an underpinning of sustainability in that specific cultural context-

"The programs that support these cultural hubs also sustain people on Country, and build strength in knowledge." [44] (p. 30)

"The diversity of our knowledge systems, and acknowledge and promote Australia's history of peopled land-and sea-scapes and our connections to Country over millennia as the way forward for sustainability." [45] (p. 108)

-along with a clear realization that different Indigenous cultural groups within Australia do have divergent notions of what sustainability entails and the difficulties that this creates in designing a national Australian Indigenous carbon economy [33] (p. 107) [34] (p. 69). For some, who have secure land tenure, the focus is on the use of traditional fire management practices:

"For example, Indigenous Peoples are building enterprises founded on their knowledge of traditional fire management and experience in burning Country the right way. In northern Australia Indigenous fire methodology, based upon a systematic mosaic approach to early dry season burns across Country, has demonstrated both greenhouse gas abatement (compared to uncontrolled wild fires) and carbon sequestration benefits." [46] (p. 69)

In contrast, other tribal groups with less secure land tenure "...are looking to secure payment for carbon offset management services through their land and sea management units" [46] (p. 69).

\section{Conclusions}

It is transcultural nuances such as these that need to be viewed in a more central light in ESE education if it is to be genuinely transformative and teach students a more accurate picture of how sustainability exists as a culturally relative concept in the modern 
era, one that is evident in the realities and practicalities of implementation. Concomitantly, for that shift to occur, there needs to a salient focus on developing transcultural capacity within ESE educators, providing them with the foundation to recognize and highlight the existence of such variations without feeling the need to homogenize ESE into one cultural perspective. In this, policymakers and educational leaders need to recognize that ESE teachers are no different from school educators who work in other learning areas; developing a transcultural mindset will enable them to "move beyond assuming that broad-mindedness and a willingness to tackle the complexity of the world at large just happen naturally in such an environment" [30] (p. 10). Space and the defined parameters of this paper do not permit a more detailed research-based discussion as to how these transcultural capacities can be developed in teachers; instead, see, for example, [31,33].

The future of ESE globally is at a form of crossroads, in that, recent global decisions, such as the setting of carbon emission targets in Australia, Europe, and some parts of Asia, have highlighted that the middle of this century is the point of sustainability no return in terms of global warming. If ESE is to prepare students for the position in which they might find their world at that time, then it needs to become fully transformative by adopting a transcultural approach to pedagogy and specifically prioritize the expertise of ESE teachers to implement such an approach. In doing so, ESE education, unlike its current state, will become not only inclusive of the existence of multiple cultural conceptions of sustainability but will also become an exemplar of how to adapt any aspect of school education to the demands of twenty-first-century global societal shifts in a constructive, transformative and effective manner.

Funding: This research received no external funding.

Conflicts of Interest: The author declares no conflict of interest.

\section{References}

1. Hargreaves, A. Changing Teachers, Changing Times: Teachers' Work and Culture in the Postmodern Age; Cassell: London, UK, 1994.

2. Rizvi, F. Towards cosmopolitan learning. Discourse Stud. Cult. Politics Educ. 2009, 30, 253-268. [CrossRef]

3. Strasser, T.; de Kraker, J.; Kemp, R. Three Dimensions of Transformative Impact and Capacity: A Conceptual Framework Applied in Social Innovation Practice. Sustainability 2020, 12, 4742. [CrossRef]

4. Saavedra, A.R.; Opfer, V.D. Learning 21st-Century Skills Requires 21st-Century Teaching. Phi Delta Kappan 2012, 94, 8-13. [CrossRef]

5. Engeström, Y.; Sannino, A.; Virkkunen, J. On the Methodological Demands of Formative Interventions. Mind Cult. Act. 2014, 21, 118-128. [CrossRef]

6. Bergmann, M.; Jahn, T.; Knobloch, T.; Krohn, W.; Pohl, C.; Schramm, E. Methods for Transdisciplinary Research: A Primer for Practice; Campus Verlag: Frankfurt, Germany; New York, NY, USA, 2012.

7. Lynch, S.; Curtner-Smith, M. 'You have to find your slant, your groove:' one physical education teacher's efforts to employ transformative pedagogy. Phys. Educ. Sport Pedagog. 2019, 24, 359-372. [CrossRef]

8. Coutts, L. Empowering students to take ownership of their learning: Lessons from one piano teacher's experiences with transformative pedagogy. Int. J. Music Educ. 2019, 37, 493-507. [CrossRef]

9. Lopez, A.E.; Olan, E.L. (Eds.) Transformative Pedagogies for Teacher Education: Moving towards Praxis in an Era of Change; Information Age Publishing, Inc.: Charlotte, NC, USA, 2018.

10. Hajer, M.; Nilsson, M.; Raworth, K.; Bakker, P.; Berkhout, F.; de Boer, Y.; Rockström, J.; Ludwig, K.; Kok, M. Beyond Cockpit-ism: Four Insights to Enhance the Transformative Potential of the Sustainable Development Goals. Sustainability 2015, 7, 1651-1660. [CrossRef]

11. Handa, N. Education for Sustainability through Internationalisation Transnational Knowledge Exchange and Global Citizenship, 1st ed.; Palgrave Macmillan: London, UK, 2018.

12. Swanson, D.M.; Gamal, M. Global Citizenship Education / Learning for Sustainability: Tensions, 'flaws', and contradictions as critical moments of possibility and radical hope in educating for alternative futures. Glob. Soc. Educ. 2021. [CrossRef]

13. Fam, D.; Neuhauser, L.; Gibbs, P. Transdisciplinary Theory, Practice and Education The Art of Collaborative Research and Collective Learning, 1st ed.; Springer International Publishing: Cham, Switzerland, 2018.

14. Maguire, K. Transdisciplinarity: Towards an Epistemology of What Matters. In Transdisciplinary Theory, Practice and Education: The Art of Collaborative Research and Collective Learning; Fam, D., Neuhauser, L., Gibbs, P., Eds.; Springer International Publishing: Cham, Switzerland, 2018; pp. 103-115.

15. Casinader, N.; Kidman, G. Geographical inquiry as a transcultural vehicle for education in sustainable development: The centrality of a new vision. Glob. Comp. Educ. 2018, 2, 49-61. 
16. United Nations Educational Scientific and Cultural Organization. Sustainable Development: The 17 Goals. Available online: https:/ /sdgs.un.org/goals (accessed on 4 April 2021).

17. United Nations Educational Scientific and Cultural Organization. The Sustainable Development Agenda. Available online: https://www.un.org/sustainabledevelopment/development-agenda/ (accessed on 4 April 2021).

18. Dewey, J. Democracy and Education; Macmillan: New York, NY, USA, 1916/1964.

19. Maude, A.M. Sustainability in the Australian Curriculum: Geography. Int. Res. Geogr. Environ. Educ. 2014, 27, 19-27. [CrossRef]

20. Organisation for Economic Co-operation and Development. Programme for International Student Assessment. Available online: https:/ / www.oecd.org/pisa/ (accessed on 4 April 2021).

21. Organisation for Economic Co-operation and Development. Preparing Our Youth for an Inclusive and Sustainable World: The OECD Global Competence Framework; OECD: Paris, France, 2018.

22. Schleicher, A. Pisa Tests to Include 'Global Skill and Cultural Awareness. Available online: http://www.bbc.com/news/business36343602 (accessed on 31 January 2017).

23. Casinader, N. Transnational Education and Thinking: Case Studies in Global Schooling; Routledge: Abingdon, UK, 2014.

24. Geertz, C. The Interpretation of Cultures; Basic Books Inc.: New York, NY, USA, 1973.

25. Nisbett, R.; Masuda, T. Culture and Point of View. In Biological and Cultural Bases of Human Inference; Viale, R., Andler, D., Hirschfield, L., Eds.; Lawrence Erlbaum Associates, Inc.: Mahwah, NJ, USA, 2006; pp. 49-70.

26. Australian Institute for Teaching and School Leadership [AITSL]. Australian Professional Standards for Teachers. Available online: http:/ / www.aitsl.edu.au/australian-professional-standards-for-teachers/standards/list (accessed on 4 April 2021).

27. Australian Institute for Teaching and School Leadership [AITSL]. We're Here for Teaching. Available online: https://www.aitsl. edu.au (accessed on 4 April 2021).

28. National Institute of Education Singapore. Nurturing Hearts and Minds. Available online: https://nie.edu.sg (accessed on 4 April 2021).

29. Yong, Z. Preparing Globally Competent Teachers: A New Imperative for Teacher Education. J. Teach. Educ. 2007, 61, 422-431. [CrossRef]

30. Reese, J.; Lewis, C.; Geneix, C. Connecting Global Issues. IS Int. Sch. 2011, 13, 10-13.

31. Casinader, N. Transnationalism and Teacher Capacity: Professional Readiness in the Globalised Age; Routledge: Abingdon, UK, 2020.

32. Casinader, N. Transnational learning experiences and teacher transcultural capacity: The impact on professional practice -a comparative study of three Australian schools. Intercult. Educ. 2018, 29, 258-280. [CrossRef]

33. Casinader, N.; Clemans, A. The building of the transcultural capacities of preservice teachers to support their employability in a globalised world: A pilot study. Intercult. Educ. 2018, 29, 589-608. [CrossRef]

34. Australian Curriculum Assessment and Reporting Authority [ACARA]. The Australian Curriculum; Australian Curriculum Assessment and Reporting Authority [ACARA]: Sydney, Australia, 2020.

35. New Zealand Government, Ministry of Culture and Heritage. The New Zealand Curriculum; New Zealand Government, Ministry of Culture and Heritage: Wellington, New Zealand, 2007.

36. Ministry of Education Singapore. Education in SG. Available online: http://www.moe.gov.sg/education/ (accessed on 4 April 2021).

37. Shuali Trachtenberg, T.; Bekerman, Z.; Bar Cendón, A.; Prieto Egido, M.; Tenreiro Rodríguez, V.; Serrat Roozen, I. Volume 1-Teachers' Intercultural Competence: Working Definition and Implications for Teacher Education; European Union: Luxembourg, 2020.

38. Martin, F. Thinking Differently about Difference. Think Global Thinkpiece 2012 Series 2012; Think Global: New York, NY, USA, 2012.

39. United Nations Educational Scientific and Cultural Organization. Transforming Our World: The 2030 Agenda for Sustainable Development; A/RES/70/1; United Nations Educational Scientific and Cultural Organization: Paris, France, 2015.

40. Samuel, G. Independent Review of the EPBC Act_Final Report; Commonwealth of Australia: Canberra, Australia, 2020.

41. Eisenhammer, S.B. Indigenous Leader as One: Mine the Amazon Basin; Nine Entertainment Co.: Melbourne, Australia, $2021 ;$ p. 17.

42. Woodward, E.; Hill, R.; Harkness, P.; Archer, R. (Eds.) Our Knowledge, Our Way in Caring for Country: Indigenous-Led Approaches to Strengthening and Sharing Our Knowledge for Land and Sea Management. Best Practice Guidelines from Australian Experiences; NAILSMA: Brinkin, Australia; CSIRO: Canberra, Australia, 2020.

43. Poelina, A.; Webb, T.; Dhimurrru Aboriginal Corporation; Smith, A.S.; Smith, N.; Wright, S.; Hodge, P.; Daley, L.; Kimberley Land Council; Bardi Jawi Niimidiman Aboriginal Corporation; et al. Foundations of Our Knowledge, Our Way. In Our Knowledge, Our Way in Caring for Country: Indigenous-Led Approaches to Strengthening and Sharing Our Knowledge for Land and Sea Management. Best Practice Guidelines from Australian Experiences; Woodward, E., Hill, R., Harkness, P., Archer, R., Eds.; NAILSMA: Brinkin, Australia; CSIRO: Canberra, Australia, 2020; pp. 2-20.

44. Hunter, B.; Smith, A.S.; Smith, N.; Wright, S.; Hodge, P.; Daley, L.; Yates, P.; Turner, A.; Mulladad, M.; Perkins, R.; et al. Strengthening Our Knowledge for Country. In Our Knowledge, Our Way in Caring for Country: Indigenous-Led Approaches to Strengthening and Sharing Our Knowledge for Land and Sea Management. Best Practice Guidelines from Australian Experiences; Woodward, E., Hill, R., Harkness, P., Archer, R., Eds.; NAILSMA: Brinkin, Australia; CSIRO: Canberra, Australia, 2020; pp. 21-60.

45. Ford, L.; Woodward, E.; Hill, R.; Tengo, M.; Harkness, P. Actions towards Best Practice to Support Our Knowledge, Our way. In Our Knowledge, Our Way in Caring for Country: Indigenous-Led Approaches to Strengthening and Sharing Our Knowledge for Land and Sea Management. Best Practice Guidelines from Australian Experiences; Woodward, E., Hill, R., Harkness, P., Archer, R., Eds.; NAILSMA: Brinkin, Australia; CSIRO: Canberra, Australia, 2020; pp. 105-117. 
46. Atkinson, G.; McTaggart Marrfurra, P.; Turpin, G.; Buissereth, R.; Medijina, B.; McMurray, L.; Foley, R.; Nyangumarta Marlpa Aboriginal Corporation; Cameron, P.A.; Schulz, L.; et al. Sharing our Knowledge in Caring for Country. In Our Knowledge, Our Way in Caring for Country: Indigenous-Led Approaches to Strengthening and Sharing Our Knowledge for Land and Sea Management. Best Practice Guidelines from Australian Experiences; Woodward, E., Hill, R., Harkness, P., Archer, R., Eds.; NAILSMA: Brinkin, Australia; CSIRO: Canberra, Australia, 2020; pp. 62-90.

\section{Short Biography of Author}

Niranjan Casinader is Adjunct Senior Lecturer in Education at Monash University and a semi-retired educational consultant. Originally educated as a geographer, he worked as a teacher and educational leader in secondary schools and international education for over 30 years before moving into academia, teaching and researching across postgraduate and graduate courses in curriculum, assessment, pedagogy, and Humanities education. He has been recognized professionally for his work as an educator in Australia and internationally. Niranjan's research remains focused on three principal strands: the impact of transnationalism and globalization in education, particularly in relation to the influence of culture on curriculum, pedagogy, and thinking; the teaching of Geography and other Humanities subjects in schools, with a particular interest in inquiry and problem-solving thinking; and the role of education in British colonial policy and practice, with an especial focus on its relevance to contemporary society. His current research projects are concerned with: (a) the building and evaluation of the transcultural capacity of teachers, with particular reference to their role in a globalized educational environment; (b) the nature of cultural education in schools, with particular emphasis on the role of geographical education; (c) the role of school alumni groups in facilitating migrant experience; (d) inquiry-based teaching and learning across the disciplines. 